\title{
Striking a balance between culture and fun: 'Quality' meets hitman genre in In Bruges
}

\section{Geoff King}

An analysis of In Bruges (2008) that situates the film as a hybrid product offering a mixture of signifiers of cinematic 'quality' and 'lower' genre ingredients. This paper also considers the extent to which In Bruges offers a combination of tonal registers in which irony and detachment, as markers of distinction, are blended with a more mainstreamoriented appeal to emotional engagement on the part of the viewer, and considers how this might be related to the broader social and industrial contexts in which it appeared.

'We shall strike a balance between culture and fun', promises Ken (Brendan Gleeson), one of the two hitmen spending an enforced break in the picturesque eponymous Belgian city of In Bruges (2008). 'Somehow, I believe, Ken, the balance will tip in favour of culture', replies a sceptical Ray (Colin Farrell), his more youthful and impatient partner. Or will it? For Ken, the emphasis is, as Ray suspects, on a kind of culture-tourism based on the historical, architectural and artistic attractions offered by the location. As far as the film itself is concerned, however, a more even balance is offered between markers of 'culture' - in that traditionally loaded sense, of 'higher culture' or 'cultured' - and what might conventionally be judged to be 'lower' generic pleasures. In Bruges can be understood, this paper argues, as a hybrid work: one that mixes cultural and more specifically cinematic resonances of 'quality', usually aimed at a particular kind of niche audience, with markers of more obviously popular or mainstream appeal. The former is partially rooted in, and motivated by, the setting, but also includes some of the formal and other qualities offered by the film. The latter is provided by the generic territory of the hitman/thriller format, the central characters having been despatched to the city in the aftermath of the accidental killing of a child by Ray during his first assignment; Ken is subsequently instructed to shoot Ray, against his wishes, an order he eventually fails or refuses to carry out, prompting the arrival in Bruges of his gangster boss, Harry (Ralph 
Fiennes), and a subsequent shootout in the streets. The two dimensions of the film are combined, in some ways incongruously but with mixed resonances that might be expected to appeal across different target audiences.

The writer and director, playwright Michael McDonagh, explains the origins of In Bruges in his own response to the city during a weekend visit, a story repeated in press coverage during the release of the film (for example, Gold 2008). On the one hand, he was impressed by the beauty of Bruges and surprised it had not featured more often as a film location. On the other, he was quickly bored by the small scale of the place. The two responses developed into two characters, the hitman plot subsequently being devised to provide a rationale for their presence in the city. As a funded, produced and theatrically distributed feature, however, the combination could equally well be read as the product of a particular commercial strategy, as is argued below. In Bruges is taken here to be a manifestation of the Indiewood zone, a part of the film landscape in which certain qualities associated with the American indie/independent (or overseas) sector are characteristically mixed with others that seem to lean more closely towards the territory of the commercial mainstream. This paper also examines a mixture of tonal registers within the text in which elements that generate a distinctive degree of irony and detachment are combined with more conventional/mainstream appeal to emotional engagement, a blend that can be linked to the specific industrial context within which the film was produced and distributed. These qualities are also considered in relation to the kinds of audience demographics, and their broader social context, with which they might be associated.

\section{'Quality' vs. more mainstream genre ingredients}

In Bruges offers numerous signifiers that seek to place it, at least partly, in the arena of 'quality' cinema with a particular kind of niche audience appeal marked as distinctive from the mainstream. This is most obvious in the treatment of the location, as suggested above. One component of the film functions as a variety of travelogue, overtly displaying the 'high' cultural attractions of the old city as a source of pleasurable spectacle for the 
viewer. The film is punctuated regularly by shots that highlight the beauty of the historical architecture, often displayed in the particularly flattering lighting of the 'magical hour' when the sun is low in the sky and offering a golden-tinted single directionality. This is noticeable, for example, in an early sequence in which Ken and Ray take a sight-seeing boat trip through the city canals. The sequence begins with a lowangle travelling shot, looking upwards at a high church tower, one side of which is lit by the early morning sun. The camera tilts down to make clear its location as a point-of-view shot from the boat, moving towards a low bridge. Another perspective on the surrounding architecture follows, the upper parts of which are, again, caught by the golden glow of early sunshine. A cut to Ken, looking upwards, establishes the previous shots as his point of view, whether more or less optically exact, and demonstrates his appreciation of the spectacle. Ray, meanwhile, sits with his collar up, hunched and glaring at Ken, clearly unappreciative and questioning the activity. 'Do you think this is good', he asks, 'going around in a boat, looking at stuff?' 'Yes, I do', replies Ken; 'it's called sightseeing', a comment followed by another forward point-of-view shot from the boat and his wistful 'ah, look at that', as another vista takes his fancy.

The invitation to look is effectively extended to the viewer, on frequent occasions during the film, whether or not the topic of sightseeing is explicitly drawn to our attention as is the case in this example. The film was widely interpreted by critics as offering, among other qualities, an effective advertisement for the historical attractions of Bruges; particularly, perhaps, the 'old world' emphasis of the medieval as an appeal to the 'new world' American gaze. This appears to be one ingredient in the selling of the film, likely to appeal to some audiences more than to others, generally on the basis of their possession of certain resources of cultural capital. The invitation to the tourist gaze was taken up in various ways, including the presence of a canal-tour short among the extras provided on the DVD, the use of the theatrical release as a hook on which to hang journalistic travel articles about the city and the creation by the Bruges tourist office of a special sightseeing map charting the locations featured in the film. It would be mistaken, however, to overstate this dimension of the film. The foregrounding of touristic spectacle - whether that provided by buildings or artworks also featured within the text, including 
Bosch's 'Last Judgement' - is not achieved at the expense of more conventional/'classical' cinematic regimes, but closely integrated with aspects of character and narrative development.

The architectural vistas provided in the boat tour sequence are clearly established as being motivated by the immediate responses of both Ken and Ray, and the broader currency of this issue as one of the primary defining features of the two protagonists. Ken, through his appreciation, is established as mature and reflective in nature; Ray as impatient and childish. In general, throughout the film, images of the medieval cityscape are used, precisely, as punctuation. They might have a function in their own right, as establishers of a particular cultural milieu in which the film claims at least a partial second-hand share, but this does not stretch beyond the bounds of the mainstreamconventional use of such images as establishing shots. Architectural vistas function most frequently as transitional devices, marking the lapse of time between scenes. At one point, for example, we are presented with a carefully composed shot looking up a length of canal towards a bridge, the sunlit buildings beyond being reflected immaculately in the water underneath. The image serves no immediate diegetic purpose but acts (entirely conventionally) as a device whereby a transition occurs between the previous night-time scene, in the hotel occupied by the protagonists, and another at breakfast the following morning. Alternatively, such shots in some instances foreground the beauty of the city but in the process more immediately of introducing sequences of character interaction (in one case, another vista directed up a stretch of canal, this time towards a church and with horse-drawn carriages passing in the foreground, is followed by a longer shot, from further behind, in which Ken and Ray can be see sitting at the water's edge, leading into a sequence of closer shots of their subsequent conversation).

The medieval cityscape is not always foregrounded at all, often being relegated into the background in favour of an emphasis on narrative or character development, even in some establishing moments. When we first see the two hitmen walking the streets, immediately after their arrival, a number of buildings are visible in the background but not in focus. Even when Ken looks across a canal towards a church, in his first sign of 
interest in the location, the vista is held out of sharp focus (although not conspicuously blurred by the use of a long lens, either). A similar balance is found in Ken's visit to the top of the famous bell tower, the setting from which he is eventually to drop to his death in the climactic stages of the film. One quite striking perspective is offered of the buildings opposite, but most of the sequence remains focused on Ken himself and the kind of panoramic vista available from the top, to which several references are made throughout the film, is denied to the viewer.

If the provision of views of the city marked as beautiful, as objects supplied to the tourist gaze, does not interfere with the regular dynamics of broadly 'classical' style, it is also significant that much of the other material of the film shares some of the visual qualities associated with the former. Director McDonagh and cinematographer Eigil Bryld frequently employ lighting effects that generate a soft golden glowing effect, combined in chiaroscuro style with patches of deep shadow, further establishing the overall 'quality' impression of the visuals. This applies to many of the interior shots in the film. In some cases, overt motivation is provided for such forms of light. One night scene in Ken and Ray's hotel room, for example, is lit by strongly directional light coming from the bathroom, while a restaurant sequence has the appearance of benefiting from the relatively low-key lighting of the venue. More generally, this kind of image quality often gives the impression of being the product of soft environmental lighting (various bedside and other lamps in hotel rooms and other such interiors).

A general pitch for 'quality' status, including the display of this kind of lighting, is made in the opening moments of the film. The first images are night-time details of architecture and statuary, caught in golden highlights produced by the city's own lighting of its historical attractions. Each of a series of images fades up from the black background of the initial credits in a manner that itself creates a 'quality' impression of subtle and nuanced transition, as do slight, smooth movements of the camera during each shot. This is accompanied by a gentle, plaintive piano theme that further adds to the overall effect of marking out a particular kind of cultural ground. Very quickly, though, 
the 'lower' generic dimension is also introduced. As the images of the city continue, a voice-over comes into play, that of Ray's Irish brogue, declaring:

After I killed him, I dropped the gun in the Thames, washed the residue off my hands in the bathroom of a Burger King and walked home to await instructions. Shortly thereafter the instructions came through: get the fuck out of London youse dumb fucks; get to Bruges. I didn’t even know where Bruges fuckin' was. [pause] It's in Belgium.

Then, under a black screen and the main title block, we hear the following exchange, marked by background atmospheric sound as more present and immediate within the diegetic world of the film:

Ray: Bruges is a shithole

Ken: Bruges is not a shithole

Ray: Bruges is a shithole

Ken: Ray, we've only just got off the fuckin' train. Could we reserve judgment on Bruges until we've seen the fuckin' place.

Ray: I know it's going to be a shithole.

The film-proper then begins, with a shot of the two walking towards a retreating camera, the piano theme continuing.

Ray's voice-over and the following interchange introduce a register clearly very different from that created in the first moments of the opening sequence. The killer/hitman on-the-run generic dimension is immediately established, the particularity of some of the reference points contributing to the 'lower' cultural associations, especially the mention of the downmarket institution, Burger King. A potentially incongruous clash is generated between the markers of 'quality' and the profanity of the language, a feature of the film that prompted negative criticism from some sources. If the initial resonances are those of higher culture, nuance and restraint, these bring 
associations with cinematic worlds of violence and wittily profane dialogue, the most prominent example of which would be the films of Quentin Tarantino, a figure with whom McDonagh's work for the stage had earlier been associated. ${ }^{1}$ This might appear to be something like an ideal Indiewood blend: signifiers of 'quality' of the kind that might be associated with the heritage cinema tradition, an established feature of the speciality marketplace, mixed with the potentially larger cross-over appeal of the 'Tarantinoesque', Tarantino having established one of the most successful speciality brands in his productions for Miramax. How successful this recipe proved is considered below, both at the textual level of how the two different dimensions are brought together in the film and in its commercial performance and critical reception. First, though, more on the deployment of the 'lower' cultural component.

If Ray stands for a rejection of 'higher' cultural materials, on the grounds of boredom and lack of interest (or, more specifically, a lack of the requisite cultural capital for their enjoyment), his character is the main source of hitman/thriller genericallyassociated action within the film. He also responds with excitement on first glimpse of a film being shot on location within the diegesis, an enthusiasm for such sources of more popular culture that stands in contrast to his lack of interest in the historical building to which he has just been introduced by Ken. As a character, it seems, he cannot help getting involved in a variety of transgressive activities - his idea, it seems, of 'fun' - that offer a particular range of vicarious pleasures to the viewer. These include: dating the drug-dealing Chloe (Clémence Poésy); assaulting a man he assumes to be an American, and the man's female partner, during their dinner at a restaurant; embarking on a sexual encounter with Chloe, one that is interrupted by another violent exchange and results in his partially blinding her partner in crime, Eirik (Jérémie Renier), by shooting him in the face at close quarters with a blank round; stealing drugs from Chloe and sharing them with an American dwarf, Jimmy (Jordan Prentice) - performing in the film-within-thefilm, on the set of which Ray met Chloe - along with Ken and a pair of prostitutes, subsequently felling Jimmy with a karate chop to the neck; and then being at the centre of the climactic violence of the film after the arrival of Harry. 
Ray's own discourse, and some of the discussions into which he is drawn by others, also leans towards the Tarantino-like side of the balance, including a number of comments that seem rather overtly to be located as distinctly 'non-PC' (not that the concept of the 'politically correct' is one that should be accepted at face value, the term tending to be used as cover for a defence of various forms of discrimination). These include the latter part of the line quoted at the start of this paper, Ray's suggestion that the balance will tip in favour of culture 'like a big fat fucking retarded fucking black girl on a see-saw opposite [pause] a dwarf', an addition to his point that appears to be an overt ticking of 'non-PC' boxes. Ray proves to have what seems to be an excessive fascination with 'midgets', as he prefers to call Jimmy when he first glimpses him on the film set, and is also prone to regular use of the epithet 'gay' as a put down, used in relation to the serving of Belgian beer in goblet-style glasses and in abuse of Eirik (a usage shared by Ray and Harry). He is also happy to engage with Jimmy in a drugfuelled debate following the latter's prediction of an upcoming war between whites and blacks. The inclusion of such material, in association with Ray, seems to be another significant part of the overall positioning strategy of the film, a marker of distinction from what might be taken to be the 'PC' dominated officially-sanctioned bastions of culture (again, how far that is really the case is debatable, but it is a commonly asserted assumption).

\section{Reconciliation?}

How, then, does the film deal with these contrary dimensions and to what extent are they reconciled? The opposition is most overtly structured into the contrasting characters of Ken and Ray, who function as a fairly standard kind of 'odd couple' in their argumentative banter. The strains between the two are reconciled, however, in a very conventional manner, through the mechanisms created by Ray's suicidal tendency (in response to his shooting of the child, with which he is not sure he can live) and the outcome of the instruction given by Harry to Ken to kill Ray, for his breach of Harry's notion of the criminal code. The fulcrum of the film is the sequence in which Ken appears, however reluctantly, to be about to do the job, only to be forestalled, with heavy 
irony, by the realisation that Ray is about to kill himself. Ken then decides that Ray deserves another chance in life and resigns himself to facing the wrath of Harry, knowing that in the absence of Ray he will be expected to carry the can. Ken acts effectively as father figure to the younger man, counselling him to do something useful with his life. $\mathrm{He}$ appears to get away with it at one moment, his refusal to fight and a declaration of love for Harry leaving the latter unable to kill him. Harry makes do, instead, with a punitive shot to Ken's leg, but the unexpected reappearance on the scene of Ray (supposed to have left for an unknown destination) eventually forces the issue. A struggle leaves Ken apparently mortally wounded from a shot to the neck, subsequently jumping to his death from the bell tower in 'noble sacrifice' to warn Ray of Harry's presence in the city.

What about the qualities of the film itself? To what extent does it bring the two dimensions together in its own fabric? The two cultural realms most strongly associated with each of the two main characters (notwithstanding the fact that Ken also remains implicated in the same violent criminal subculture as Ray) could almost have been designed to illustrate the domains of certain aspects of middle- and lower-class culture outlined in Pierre Bourdieu's Distinction, the classic work on the operations of cultural capital. The taste preferences of working class culture are encapsulated for Bourdieu in terms such as 'coarse', 'vulgar' and 'profane' - as might be applied to much of the language of In Bruges, in addition to the hitman-thriller dimension more generally, with its basis in moments of actual or impending violence - as opposed to the 'sublimated', 'refined' and 'distinguished' pleasures taken by members of the segments of the middle class who invest most strongly in cultural products such as the kinds of historical architecture and works of art on display and appreciated by Ken in In Bruges (Bourdieu 1984, 7). Ken might be taken, in this respect, to be a character with aspirations towards upward social mobility from the realm implied by his day job. There are dimensions in which In Bruges does seem to constitute a integrated fabric that draws simultaneously on both its 'higher' cultural more distinctive and 'lower' cultural more mainstream-oriented strands, although this may not entirely be the case. 
The net effect to which the film appears to aspire is to create a genre-oriented piece that brings elements of 'quality' to the generic territory; that is, to the generic territory itself, rather than just in the use of the resonances of the background setting. This is achieved to a large extent through the kind of character development outlined above. In Bruges presents itself as a character study in which the protagonists have a degree of depth beyond that merely of their roles in the generic framework. This is manifested by Ken's appreciation of the attractions of Bruges, along with that of Harry, who chose the location in a misguided gesture designed to offer Ray a final pleasure before his death. Some of this is a dimension that has as much in common with the Tarantino-type spin on such material as anything of 'higher' cultural provenance, however, seeming particularly reminiscent of some of the character-colour material of Pulp Fiction (1996). The same could be said of dialogue scenes that revolve around the rights and wrongs of life as a hitman on questions such as who might or might not be the deserving victim of violent assault. What In Bruges seems to pitch for in some of this material is an overtly 'quirky' quality, as often associated with works from the indie and/or Indiewood sectors. Examples include exchanges between Ray and Ken about the likelihood of one past victim of the latter, a lollipop man, being an exponent of karate. Another character who features strongly in this dimension is the markedly quirky Yuri (Eric Godon), Harry’s local purveyor of weaponry, with his repeated querying of whether or not 'alcoves' (pronounced in a very particular northern European manner) is an appropriate English language term and his enthusiastic reaction to the suggested alterative of 'nooks and crannies', as ideal places he recommends to Ken in which to carry out the shooting of Ray. This is, again, a device that seems designed to add a degree of depth and texture (or, indeed, its own nooks and crannies), in this case to an otherwise minor functionary character.

The narrative structure of the first part of the film might be taken as another marker of a relatively 'quality' stance, departing from the norms of the hitman/crimethriller generic terrain. After the initial establishment of the situation in the opening voice-over, a relatively long delay of 42 minutes is allowed before the crux of the plot is revealed in Harry's demand that Ken kill Ray. Up to this point, in the generic territory, 
the film risks the kind of accusation that Ray makes about Bruges: that nothing much happens or that boredom might result for those expecting more exterior action or event. The film builds quite slowly, well beyond the usual length of an opening act, during which time the emphasis is on the establishment of the central character relationship. It is also worth noting that the combination of golden-tending light and deep shadow features in some of the sequences at the heart of the hitman drama, when it does reach its crisis, as well as in the earlier stages of the film and the evocation of place. This includes the scenes featuring Ken and Harry at the top of the bell tower and their subsequent struggle on the stairway. If some markers of quality continue into the latter stages, however, these are combined with more signifiers of 'lower' genre-film culture, including the rather implausible nature of the fast-moving sequence of action and events that leads eventually to Harry's suicide (his response, according to his previously expressed code of honour, to what he thinks is his own accidental killing of a child: the shooting of Jimmy, dressed in a schoolboy uniform on the film set). A tone strikingly different from that of the rest of the film is adopted in the preceding scenes, in which Harry fires at Ray while chasing him through the streets to the accompaniment of a heavy guitar and drum theme of the kind that might be expected in a much more conventionally action-centred thriller. Another gesture that seems lower-culturally located in its associations is the grotesque nature of the 'splat' with which Ken's body hits the ground after his plunge from the tower.

\section{Irony, distance, reflexivity}

An ironic and sometimes absurdly incongruous tone is another important marker of distinction in the film, inviting distance at the textual level between the viewer and any more direct implication in the on-screen events. This is the product of some of the events and also much of the dialogue, including some of the quirky elements cited above. A heavy irony governs the sequence in which Ray's imminent suicide attempt forestalls his shooting by Ken, as suggested above, one that subsequently confounds Harry: if Ken was reluctant to kill his partner, the job could have been done for him, but we are led to understand Ken's position, however inconsistent his action might seem in one respect. 
Having been stopped at the last moment, Ray is then - understandably, perhaps, but also ironically - somewhat outraged to realise that Ken was about to kill him. 'You were gonna kill yourself,' responds Ken, as if that were a justification. Ray: 'I'm allowed to.' Ken: 'No you're not'. Ray: 'What? I'm not allowed to and you are? How's that fair?' Ironic and/or somewhat absurd dialogue of this kind has been established, by this point, as one of the characteristic features of the film.

The extensive use of profanity also creates a distinctive and stylized texture, rather than merely seeking to replicate what might be imagined to be the fruity dialogue of such characters in the real world. Such dialogue takes on a deadpan, profane, almost poetic life of its own in some sequences, a quality introduced in the opening exchange cited above. This is a direct inheritance from McDonagh's darkly comic writing for the stage in works such as the Leenane Trilogy (first performed in 1996 and 1997), The Lieutenant of Inishmore (2001) and The Pillowman (2003). Another example comes during a dramatically crucial series of exchanges towards the end between Ken and Harry, after the latter's arrival in the city. Ken is discussing the need to give Ray another chance on the basis of his ability to change, in contrast to a figure such as Harry himself, who Ken suggests has only 'the capacity to get fucking worse!' The exchange continues:

Ken: Harry, let's face it, and I'm not being funny, I mean no disrespect. You're a cunt. You're a cunt now, you've always been a cunt, and the only thing that's gonna change is that you're going to become an even bigger cunt. And maybe have some more cunt kids.

Harry: Leave my kids fucking out of it! What have they done? You fucking retract that bit about my cunt fucking kids!

Ken: I retract that bit about your cunt fucking kids. Harry: Insulting my fucking kids? That's going overboard, mate! Ken: I retracted it, didn't I? [pause] That still leaves you being a cunt... Harry: Yeah, I fucking got that! 
The discourse seems incongruous on several counts. Harry does not seem offended at the initial, substantial, accusation that he is 'a cunt', which might in itself be expected to provoke a reaction in so delicate a situation. His objection is to the comment about his kids, which might seem fair enough, but it is the repeated nature of the refrain 'cunt fucking kids' that lifts it out of the realm of what might be an approximation of 'gangster talk', real or imagined, and creates a more distanced and formalised impression. The deadpan rhythms, the repetition and the incongruity is closely akin to the dialogue style of McDonagh's plays, the theatrical association offering another marker of quality for the knowing viewer. This is a dimension in which the blending of 'higher' and 'lower' cultural associations is particularly close, the markers of 'quality' inhering within (rather than merely alongside) those of the 'crude'.

In Bruges also offers a number of self-reflexive elements that add to the dimension of ironic distancing from the events of the diegetic universe. These include self-conscious reference to the use of profane language itself, following the telephone message left by Harry with the proprietor of the hotel in which Ken and Ray are staying. Harry's message, neatly typed up by the pregnant Marie (Thekla Reuten), is a tissue of verbal abuse:

Number one, why aren't you in when I fucking told you to be in? Number two, why doesn't this hotel have phones with fucking voicemail on them and not I have to leave messages with the fucking receptionist? Number three, you better fucking be in tomorrow night when I fucking call again or there'll be fucking hell to pay, I'm fucking telling you. Harry.

The message is initially delivered to us in voice-over by Fiennes, as it is read by Ken, but we also see it as a piece of text, here and when subsequently passed by Ken to Ray. The effect is an additional foregrounding of the stylized nature of such repeated profanity, further highlighted when Ken's apologises to Marie on Harry's behalf. Ken's apology underlines the mediating role his character plays in the film between the realm of hardened criminals and that of the 'civilized' world; he can swear with the best of them, 
as seen above, but unlike Harry he seems to know what is or is not the appropriate occasion for such discourse. The concentrated use of such language in some sequences throughout the film is also likely to play a prominent part in establishing boundaries around the target audience for the film, clearly having the potential to alienate some constituencies, including some of those which might otherwise be attracted by the quality or heritage dimensions of the piece.

A more overt source of reflexivity is the presence of the film-set within the film. The film-being-made-within-the-film is described by Chloe as not quite a pastiche of or homage to Nicolas Roeg's Don't Look Now (1973), but as giving a 'nod of the head' to the earlier film (in a dream sequence involving Jimmy). This phrase nicely captures what In Bruges itself seems to do, by including such a reference. Or we might term this a metareference, a one-degree more distanced reference to the process of referencing (something that, as we might expect, passes straight over the head of Ray). The film then makes its own more direct 'nod' via a conventional mechanism, glimpses of another film being watched on television by Ken in the hotel room, Orson Welles' Touch of Evil (1958), which might be taken as further evidence of his cultural literacy. These are appropriate sources for In Bruges to acknowledge, as part of its own position marking, each being a canonised example of the combination of generic dimensions (chillermystery and thriller, respectively) and aspirations towards, or recognition for, more 'artistic' quality. McDonagh also includes a characteristically more self-deprecating quip, in Jimmy's judgement of the film-within-the-film - and, potentially, for detractors, of In Bruges itself - as a 'jumped up Eurotrash piece of rip-off fucking bullshit'.

A further element of reflexivity comes at the start of the climactic sequence in which Harry finds and eventually mortally wounds Ray. Harry arrives at the hotel, where his path up the stairs is blocked by Marie. Ray asks Marie to leave, but she refuses, which creates a brief stalemate. Marie suggests they both put their guns down and go home, to which Harry replies: 'Don't be stupid. This is the shootout', implying that they are both engaged in a prefabricated generic routine, following what the script demands of such a situation. The comment seems to create potential for a more distanced response from the 
viewer, an overt acknowledgement that this is part of a formulaic template with which they are likely to be familiar as a fictional device. How far this is likely to disrupt any closer engagement with the plight of the characters remains open to question, however, particularly in this generic terrain, the acknowledgement of cinematic reference points by such figures within the diegesis having been established as a marker of textual quality or 'sophistication' in this region by other texts, most notably The Sopranos (1999-2007). The simultaneous use of and reflexive reference to such generic ingredients is another indicator of the two levels at which In Bruges functions.

Following the comment about the shootout comes a proposal from Ray, a solution to the dilemma that makes it sound like some kind of game. Ray suggests that he goes back into his room from the top of the stairs and jumps out of the window into a canal to see if he can swim to the other side and escape; Harry is to run outside and around the corner and can shoot at Ray from there, leaving Marie and her baby safely out of the action. In the exchanges that follow, the scenario sounds increasingly childish:

Harry: Do you completely promise to jump in the canal? I don't wanna run out there and come back in ten minutes and find you fucking hiding in a cupboard. Ray: I completely promise, Harry. I'm not gonna risk having another little kid die on me.

Harry: So, hang on, I go outside and then I go which way, right or left? Ray: You go right, don't ya. You can see it from the doorway. It's a big fucking canal!

Harry: Alright! Jesus! I've only just got here, haven't I? Okay. On a count of 'One, two, three, go'. Okay?

Ray: Okay. (pause)

Ray: What, who says it?

Harry: Oh, you say it.

Marie: You guys are crazy!

Ray: Ready? 
Harry: Ready.

Ray: Set

Harry: Set

Ray: (pause) One-two-three, go!

The result, again, is the creation of a discursive register than seems incongruous in the context of the actions involved and one that creates an additional measure of distance between the events and the viewer. As with Ken's intervention to prevent Ray's suicide, what is involved is a logic - it all makes a certain sense - but a logic of the absurd in which a disjunction occurs between the comic element that this produces and the matters of life and death at stake in the diegetic universe on screen.

In its employment of various sources of distancing, such as irony, incongruity and elements of reflexivity, In Bruges has something in common with Jeffrey Sconce's (2002) widely cited definition of the new American 'smart film' of the 1990s, a category defined according to an attitude of ironic detachment and dampened affect. This attitude, for Sconce, is a key ground on which a particular group of indie and/or Indiewood films mark their distinction from mainstream norms, providing scope for viewers to make their own distinctions on the basis of 'getting' the dark humour that is usually involved. The position of such viewers is contrasted by Sconce to that of conservative commentators who decry such films for their emphasis on negativity and nihilism at the expense of any positive engagement in the contemporary social terrain they traverse. A distinct element of detachment is found in the three releases from 1998 with which Sconce begins his account, Happiness, Your Friends and Neighbours and Very Bad Things. But, as James MacDowell argues (2009), Sconce tends to overstate the extent to which this characterizes all of the films and filmmakers to which he attributes the 'smart' label, many of which offer a more complex mixture of the ironic/detached and the more positively, sincerely and emotionally engaged. The latter can also be said of In Bruges.

\section{From irony to sincerity}


For all of its darkly stylized dialogue, logical absurdity and moments of self-reference, implicit or otherwise, the film has what appears to be a sincerely-intended core and what can ultimately be described as a kind of 'message', and this constitutes a key part of what it offers to the viewer. The dark humour and stylized use of profanity act, to some extent, as a defensive layer. They function this way for the characters themselves, as a kind of protective gallows humour, but the effect might also apply to the viewer, offering insulation from the full impact of otherwise more painful narrative situations such as the agony felt by Ray about killing the child and Ken's self-sacrificing attempt to save him. These rhetorical devices render the events as part of a stylized fabrication the impression created by which is very different from that which might result from the adoption of a more immediate-seeming form of realism. The latter would, of course, remain a cinematic construct in its own right, but one designed to create an impression of harsher verisimilitude that would heighten the painful emotional impact of events (think, for example, of the texture of the films of the brothers Dardenne). This is not to say that the film is evacuated of emotional impact, however, or proximity to the dilemmas of the two protagonists. We are clearly meant to experience a strong impression of the genuinelycoded remorse and sincerity of Ray, underlying the black humour generated by himself as character or the film itself.

In Bruges adopts a quite clearly and directly melodramatic, emotion-wringing tone in some of the sequences in which Ray's remorse is most outwardly expressed, in relation to both Ray himself and the paternal support offered by Ken. Overtly demonstrative indications of these emotional realms come in close proximity to some of the markers of ironic distance considered above. The dialogue riffs about the lollipop man and the chances of his having known karate come amid a conversation about religion and morality, sparked by a viewing of the 'Last Judgement' in a museum. Ray asks Ken whether he believes in 'all that stuff', a question clearly related to his own predicament. Ken proceeds, in quietly earnest register, to offer something of his philosophy, a belief in leading a good life. This is quirkily and modestly indicated ('like, if there's an old lady carrying her shopping home... Well, I don't try and help her carry her shopping, I don't go that far, but I'll certainly hold the door open for her and that and let her go out before 
me') but also with what is marked as a heart-felt quality, the two registers being closely mixed.

The references to the lollipop man - the one among Ken's past scalps that seems to cause him most remorse, the uninvolved brother of an intended victim - are comical and absurd, but also lead directly back to a focus on Ray's killing of the child. 'I killed a little boy. You keep bringing up fuckin' lollipop men', he declares, breaking into tears. This directly emotive material then leads into another riff from Ray, in which stylized/distanced and more serious/sincere content are closely interwoven, following Ken's reassurance that he had not meant to kill the boy.

I know I didn't mean to. But because of the choices I made, and the course that I put into action, a little boy isn't here any more. And he'll never be here again. [pause] I mean here in the world not here in Belgium. [pause] Well, he'll never be here in Belgium either, will he? I mean, he might've wanted to come here when he got older. I don't know why. And that's all because of me. He is dead because of me. And I'm trying to... trying to get my head around it but I can't. I will always have killed that little boy. And that ain't ever gonna go away. Ever. Unless, maybe, I go away.

Most of this speech is shot in a tight, head-and-shoulders close-up of Ray facing towards the camera (although his gaze wanders), confronting the viewer more or less directly with his grief. The mode of expression is hesitant and the imagery plain, dominated by the dark bulk of Ray's jacketed shoulders, and without any of the golden light so widely used elsewhere in the film. The overall emphasis is that of a seriously and sincerely-coded painful modality, only slightly leavened in this case by the discursive detour entailed by the following through of the literal logic relating to what exactly is signified by the initial 'here' from which the boy was rendered absent.

A similar effect is created in the latter part of the averted-suicide sequence, the irony of the initial situation and some of the resultant banter being followed by another 
straightforward emotional declaration by Ray ('Ken! I killed a little boy!') and his breakdown into tears. At this point Ken is given one of his most earnestly sincere speeches, after he embraces Ray, urging him to 'save the next little boy.' A gentle musical underscore is used subtly to reinforce the current of emotional engagement in this moment. Any such accompaniment is absent, however, from the 'lollipop man' sequence, an indicator of the somewhat harsher impression of emotional pain articulated in that case.

The combination of these qualities - the ironic, darkly comic, somewhat detached and the more sincerely-coded emotional engagement - is a key part of the dual address offered by the film. Viewers are offered the distinctive, and distinction-marking, pleasure of the particular qualities of the dialogue and other ironic and/or distancing effects, but combined with a more mainstream-conventional invitation to engage with the emotional experiences of the characters. If the former is the particular selling point of the film, as a distinctive individual work within its generic territory, the latter is the more familiar ground - characteristic of most if not all variations of commercially distributed feature films - within which this is established. The dimension of sincere emotional engagement is far less present amid the often controversial brutalities enacted in McDonagh's plays, a ground on which they have been criticised by some commentators (see Murphy, 2006, Burke 2006). Its centrality to In Bruges can be taken as a marker of the more mainstream imperatives involved in the production of commercial cinema. A connection might also be suggested between the ways these qualities operate, in concert, and some of the likely target audiences of the film.

\section{Audience appeal?}

One of the central arguments in Sconce's account of 'smart' cinema is that the appearance of films evidencing these characteristics during the 1990s can be related to certain aspects of their broader socio-cultural context. The smart film, for Sconce, is designed to appeal to a specific demographic: a relatively young, educated, urban 'bohemian' audience, often associated somewhat loosely with the notion of the existence 
of a 'Generation X', a disaffected post-baby-boom generation said to have 'retreated into ironic disengagement as a means of non-participatory coexistence with boomers and their dominance of the cultural and political landscape' (355). While cautious on its status as a fully-realized or clear-cut phenomenon, Sconce suggests that the 'Gen-X' label became 'a popular point of identification' for some members of the educated white middle class: 'Mobilizing irony as a tactic of disaffection, a certain social formation (defined perhaps more by bohemian aspirations than generational boundaries) created a culture of semiotic exile during the 1990s, reading "against the grain" of so-called mainstream culture while cultivating a "new voice" of cynical detachment' (356-7).

If Sconce's argument about the nature of many of the works he includes in the smart category overstates their degree of detachment, however, much the same might be said of his understanding of how they might appeal to audiences located within this kind of demographic territory, a ground on which MacDowell again makes the case for a revision of the Sconce position. Films such as In Bruges seem to make an appeal to an audience that embraces both ironic detachment and a desire for more sincere engagement, a sensibility encapsulated in MacDowell's account by the term 'Romantic irony'. MacDowell draws here on the work of the Dutch philosopher Jos de Mul (1999), who defines Romantic irony as a contemporary sensibility resulting from a blend of traits associated with modernism (optimism and belief in progress) and postmodernism (ironic detachment as a result of belief in relativism and plurality). This is not, for de Mul, a reconciliation of the differences between the two poles but an ambivalent position, the resulting experience being one that 'oscillates between modern enthusiasm and postmodern irony' (25).

A film such as In Bruges can be understood as being targeted at an audience for which irony and detachment is one particular ground of appeal. This might be an audience - defined in some of the ways suggested by Sconce, although perhaps in need of some updating to the later 2000s - the social-cultural experience of which is one that encourages a distinction-marking distancing from certain qualities associated with the mainstream. But the film seems also to appeal to a desire for engagement, one that, as 
MacDowell suggests via de Mul, might also be an important component of the contemporary sensibility (it is less clear in de Mul's account, however, whether this is associated with any particular demographic, rather than society as a whole). The strain of ironic detachment in In Bruges permits the more conventional sincere emotional engagement to be enjoyed while at the same time offering qualities that can be consumed as markers of distinction for viewers who might, in the process, thereby mark their own points of distinction from a certain version of the mainstream. The layers of irony and excess profanity can be seen as offering a kind of cover, potentially, for some viewers, for more familiar processes of emotional engagement which, on their own, might be considered to be too conventional, naively mainstream or 'square'. But it could also be argued that the kinds of audience groups identified by Sconce are likely actively to seek this degree of emotional engagement and sincerity, as a source of pleasure in its own right, alongside or in combination with the particular pleasures of irony. MacDowell associates this with what he terms 'a general growing desire - particularly among a younger generation' - to find some way beyond the nihilism or fatalism often associated with the postmodern. No specific social ground is identified for the existence of this desire, although it is associated by MacDowell with a broader embracing by some commentators of the notion of a 'New Sincerity' in various aspects of popular culture, including film and music.

The term 'New Sincerity' was coined in relation to film by Jim Collins (1993), in a study of different trends in some Hollywood genre films in the early 1990s. Collins focuses on two tendencies, each of which he associates with the proliferation since the 1980s of access to media texts through the widespread adoption of new technologies such as the VCR. A key dimension of the texture of postmodern cultural life, in this and many other accounts, is an intermingling of old and new texts, constituting what Collins terms 'the array', 'the perpetual circulation and recirculation of signs' (246). One response to this situation identified by Collins is the production of genre films that offer dissonance, in an ironic and eclectic juxtaposition of elements that clearly do not belong together, his main example of which is Back to the Future III (1990). Another response 'to the same media-sophisticated landscape' (257) takes an opposite tack, seeking a return to a pre- 
ironic state of sincerity, as manifested for Collins by examples including Dances With Wolves (1990) and Field of Dreams (1989). In this account, the ironic and the sincere are separated out, into different kinds of genre films, although this is something of an oversimplification given that some measure of sincerity is rarely entirely absent from Hollywood features (including the likes of Back to the Future III, which still invites considerable emotional proximity to the central characters). In MacDowell's account, however, and my reading of In Bruges, the two components tend to be combined in a manner that seems likely to have particular appeal to the kind of target demographic outlined above (it might also be argued that some combination of the two is also more typical of the Hollywood mainstream than either of the alternatives identified by Collins). The sincere dimension might also function as a marker of quality in its own right for some viewers, including those who might be less comfortable with the level of irony and profanity generated by the film.

The notion of a 'New Sincerity', as a counter to the irony often taken to characterize parts of recent/contemporary media discourses, has been taken up in various spheres, including film and broader areas of American culture. One of the earlier usages was in relation to a number of alternative rock bands in the late 1980s. The concept was celebrated in the mid 2000s by the young radio host and podcaster Jesse Thorn, a source cited by MacDowell, whose 'Manifesto for The New Sincerity' (2006) described it as 'irony and sincerity combined [...] to form a new movement of astonishing power.' It was used in relation to late 1990s indie film by Mark Olsen (1999), writing in Film Comment, in a celebration of the first two features of Wes Anderson, a figure declared to stand against the prevailing trend in that he 'does not view his characters from some distant Olympus of irony' (12). This is a stance in which Olsen seems to differ from prevailing opinion, in which Anderson is often cited as an exponent of dry, ironic style. Like Sconce, however, Olsen tends to exaggerate the extent to which qualities such as sympathy and allegiance towards character are absent from the work of Anderson's contemporaries, either in Hollywood or the independent sector. The filmmakers to which he places Anderson as most in opposition, in what he terms 'the arch-irony cult', are Todd Solondz, Gregg Araki and 'that ironist old-timer Hal Hartley' (12). The work of 
these three does offer plenty of ironic distance, but this is far from always at the expense of any more sincere engagement. Araki's most stylized feature, The Doom Generation (1995), for example, still invites some attachment to the central characters, especially the somewhat naïve Jordan (James Duval). Emotional engagement is also possible in Solondz's Happiness, a key example of Sconce's smart film, despite its very strong vein of irony. The 'newness' of this New Sincerity seems somewhat overstated, as is often the case in such discourses, largely as a result of the exaggeration of the extent to which irony was ever a single or dominant note, either in indie film or American culture at large.

\section{Industrial context: Indiewood and international partnership}

The combination of qualities offered by In Bruges can be related quite directly to the immediate industrial context in which the film was produced and distributed, particularly through the involvement of Focus Features, the speciality division of the NBC-Universal studio-conglomerate and a quintessential Indiewood institution. ${ }^{2}$ In addition to being a characteristic Indiewood manifestation of more and less mainstream-oriented components at the textual level, the film also embodies a contemporary tendency for the development of partnerships between divisions such as Focus and overseas sources of both production and revenue. The production, based on a spec script by McDonagh, was produced by London-based Blueprint Pictures, the strategy of which has been to develop projects budgeted between $\$ 10$ and $\$ 20$ that can attract finance from the speciality arms (Dawtry 2007). It can be understood, then, as a project specifically targeted at the Indiewood arena. The film was jointly funded by Focus and the renascent British producer Film4, the former retaining worldwide distribution rights. The importance of international partnerships of this kind was underlined by the subsequent merger of the Focus international sales and distribution arm, Focus International, with Universal's broader International Production Group, a move said by Focus CEO James Schamus to be designed to give filmmakers 'one-stop shopping with more global focus' (Thompson 2009). Arrangements with overseas sources can be a valuable source of the 'quality' resonances often associated with certain kinds of international productions (including 
those with British or other European 'heritage' associations). Such films can also be well positioned to succeed in the overseas marketplace, partly as a result of the geographically-specific aspects of their own fabric, as in the case of the British and continental European dimensions of McDonagh's film. In Bruges performed disappointingly at the US box office, grossing only $\$ 7.8$ million, barely more than half its $\$ 15$ million budget, but took more than three times as much in the overseas market, contributing to a more respectable total theatrical return of $\$ 33$ million (figures from boxofficemojo.com).

It is tempting to suggest that the different qualities of In Bruges might be mapped onto the US/Anglo-Irish or European dimensions of the film, the former tending to be associated more strongly with popular genre productions, the latter, particularly as experienced in the US market, with the quality sector. This would be an oversimplification, of course, not least in the context of existing British crime/gangster traditions. Some such geographically-oriented distinction is mobilized within the film itself, however, in what can be taken to be distinction-marking gestures, opposed to certain understandings of what is signified by 'America'. These include the presence of a group of comically overweight American tourists, with whom Ray tangles in the early stages, and Ken's comment to Jimmy, after learning that he is from the US, to 'try not to say anything too loud or crass'. Such elements might not have helped the performance of the film in the American market, although a warning is included, implicitly, to caution against the dangers of the imposition of such stereotypical assumptions. Ray's antagonism of the character he assaults during the dinner with Chloe, which includes references to the Vietnamese and the murder of John Lennon, is based on his failure to identify the difference between Americans and Canadians, an error that proves to have fatal consequences (it is Ray's arrest for the assault that brings him back to Bruges, sealing his fate and that of both Ken and Harry).

How far In Bruges really succeeds in reconciling its different dimensions at the textual level remains a matter for debate. The film was generally well received critically, receiving a rating of 81 per cent on the Rotten Tomatoes review-aggregation website 
(121 out of 150 judged to be 'Fresh', 29 'Rotten'), even if some expressed reservations, particularly in regard to the action of the latter stages. ${ }^{3}$ Viewer responses, as gauged here by examination of a sample of 155 'customer reviews' posted on the Amazon.com website, give an indication of some of the grounds on which the film was either approved or rejected. ${ }^{4}$ The overwhelming focus of highly positive responses is on the mixture of comic and darker or tragic tones achieved by the film, while the strongest rejection comes, unsurprisingly, from a minority who find the blend of comedy and violent action to be offensive or who reject the notion that such material can be comic at all.

Respondents on both sides of this divide are critical of promotional materials for giving the impression that the film was a more conventional comedy, a somewhat typical tendency of marketing departments to emphasise what they see as the potentially more widely appealing dimensions of films of this kind. Positive reviews strongly outnumber the negative on Amazon (ratings break down as follows: 5 star, 84; 4 star, 37; 3 star, 15; 2 star, 4; 1 star, 15), although the total number of reviews is relatively low, which suggests a film that has not achieved the widespread penetration of the most successful Indiewood products, for which a typical number of responses can be in excess of 1,000. This might be suggestive of the relatively limited constituency likely to invest in the particular nature of the mixture of tones offered by the film. Even with its greater success overseas than in the US market, In Bruges was a distinctly modest performer at the box office and can be taken as an example of the difficulty in some cases commercially, at least, whatever judgement is made of its artistic or other merits - of combining different bases of likely audience appeal, the ingredients of which can clash awkwardly, for some viewers, rather than necessarily offering a smooth blend.

\section{Notes}

1. See various contributions to Chambers and Jordan 2006.

2. For more general background on Focus, see King 2009, chapter 5, 'Indiewood in Focus'.

3. The trade press review in Variety, for example, found the film 'overly far-fetched once the action kicks in' and predicted 'a generally indifferent critical and aud response' 
(Koehler 2008). Among other prominent sources, The New York Times was also lukewarm in its response (Dargis 2008) while one of the leading online forums, Salon.com, questioned the blend of qualities offered by the film (O’Hehir 2008). 4. Accessed 17 August 2009, starting at http://www.amazon.com/Bruges-ColinFarrell/product-

reviews/B0018BD9DA/ref=cm_cr_pr_link_1?ie=UTF8\&showViewpoints=0\&sortBy=by SubmissionDateDescending. The usual qualifications need to be made about the use of Amazon reviews, or other such sources, as indications of viewer responses. This is, clearly, a self-selected sample that should not necessarily be taken to be representative, although Amazon does have the merit of tending to canvas a wide sample of viewers.

\section{References}

Bourdieu, Pierre. 1984. Distinction: A Social Critique of the Judgement of Taste. London: Routledge.

Burke, Patrick. 2006. "'Like the Cat-astrophe of the Old Comedy": The Animal in The Lieutenant of Inishmore'. In The Theatre of Martin McDonagh: A World of Savage Stories, ed. Lilian Chambers and Eamonn Jordan, 60-78. Dublin: Carysfort Press.

Chambers, Lilian, and Eamonn Jordan, ed. 2006. The Theatre of Martin McDonagh: A World of Savage Stories. Dublin: Carysfort Press.

Collins, Jim. 1993. 'Genericity in the Nineties: Eclectic Irony and the New Sincerity'. In Film Theory Goes to the Movies, ed. Jim Collins, Hilary Radner and Ava Preacher Collins, 242-263. New York \& London: Routledge.

Dargis, Manohla. 2008. 'Hit Men on Holiday Get All Medieval'. The New York Times, 8 February. Accessed online at http://movies.nytimes.com/2008/02/08/movies/08brug.html

Dawtry, Adam. 2007. 'Producers seek Blueprint for success'. Variety. Posted at Variety.com 17 March, http://www.variety.com/article/VR1117961300.html?categoryid=1246\&cs=1 
De Mul, Jos. 1999. Romantic Desire in (Post)modern Art and Philosophy. Albany: State University of New York Press.

Gold, Sylviane. 2008. 'Film; A Dark-Humor Master Gets a Camera'. The New York

Times, January 13. Accessed online at http://www.nytimes.com/2008/01/13/movies/13gold.html

King, Geoff. 2009. Indiewood, USA: Where Hollywood meets Independent Cinema. London: I.B.Tauris.

Koehler, Robert. 2008. 'In Bruges'. Posted at Variety.com, 17 January, http://www.variety.com/index.asp?layout=festivals\&jump=review\&id=2471\&rev iewid=VE1117935823

MacDowell, James. 2009. 'Notes on Quirky'. Paper presented at 'American Independent Cinema: Past, Present, Future', May, Liverpool John Moores University.

Murphy, Paul. 2006. 'The Stage Irish Are Dead, Long Live the Stage Irish; The Lonesome West and A Skull in Connemara'. In The Theatre of Martin McDonagh: A World of Savage Stories, ed. Lilian Chambers and Eamonn Jordan, 60-78. Dublin: Carysfort Press.

O'Hehir, Andrew. 2008. 'Mobsters in a medieval wonderland'. Salon.com, 18 January, http://www.salon.com/ent/movies/btm/2008/01/18/sundance1/

Olsen, Mark. 1999. 'If I can dream: The Everlasting Boyhoods of Wes Anderson Review'. Film Comment 35, no. 1: 12-17. Accessed online at http://findarticles.com/p/articles/mi_m1069/is_1_35/ai_53705833/

Sconce, Jeffrey. 2002. 'Irony, nihilism and the new American "smart' film"'. Screen 43, no. 4: 349-369

Thomson, Anne. 2009. 'Breaking News: Focus Features Goes Global'. Thompson on Hollywood weblog. Variety.com, 14 January, http://weblogs.variety.com/thompsononhollywood/2009/01/breaking-news-focusfeatures-goes-global.html

Thorn, Jesse. 2006. 'Manifesto for The New Sincerity'. www.maximumfun.org/blog/2006/02/manifesto-for-new-sincerity.html 